\title{
Toxicopathological interaction of lead and cadmium and amelioration with N-Acetyl-L-Cysteine
}

\author{
B. Anilkumar ${ }^{1}$, A. Gopala Reddy ${ }^{2}$, A. Anand Kumar ${ }^{3}$, G. Ambica ${ }^{4}$ and C. Haritha ${ }^{5}$
}

1. Department of Pharmacology and Toxicology, College of Veterinary Science, Korutla, Andhra Pradesh, India;

2. Department of Pharmacology, College of Veterinary Science, Rajendranagar, Hyderabad, Andhra Pradesh, India;

3. Department of Veterinary Pathology, College of Veterinary Science, Proddatur, Andhra Pradesh, India;

4. Department of Veterinary Medicine, College of Veterinary Science, Korulta, Andhra Pradesh, India;

5. Department of Pharmacology, College of Veterinary Science, Rajendranagar, Hyderabad, Andhra Pradesh, India

Corresponding author: B. Anilkumar, email: anilvetpharma@gmail.com

Received: 01-07-2013, Revised: 05-08-2013, Accepted: 06-08-2013, Published online: 13-09-2013

doi: $10.14202 /$ vetworld.2013.823-827

How to cite this article: Anilkumar B, Gopala Reddy A, Anand Kumar A, Ambica G and Haritha C (2013) Toxicopathological interaction of lead and cadmium and amelioration with N-Acetyl-L-Cysteine, Veterinary World 6(10): 823-827.

\begin{abstract}
Aim: To investigate the nephrotoxicity induced by the combined exposure of lead $(\mathrm{Pb})$ and cadmium $(\mathrm{Cd})$ and its amelioration with $\mathrm{N}$-acetyl-L-cysteine (NAC).

Materials and Methods: To evaluate the nephrotoxicity of $\mathrm{Pb}$ and $\mathrm{Cd}$, the present study was taken up with a total of 48 male wistar rats, divided uniformly into eight groups each with 6 rats. Groups I and II were kept as untreated control and NAC control, respectively. Groups III, IV and V served as toxic control groups viz., $\mathrm{Pb}, \mathrm{Cd}$ and combination of $\mathrm{Pb}+\mathrm{Cd} @ 1000,300$ and 1000+300 ppm, respectively. Whereas groups VI, VII and VIII were co exposed with NAC and served as therapeutic groups ( $\mathrm{Pb}, \mathrm{Cd}$ and combination of $\mathrm{Pb}+\mathrm{Cd} @ 1000,300$ and 1000+300 ppm, respectively and NAC @ 300mg/ kg). The experiment was carried out for 3 months and kidney tissues were collected for histopathological and electron microscopic study at the end of the experiment.

Results: Histopathological examination of kidney tissue revealed marked alterations and electron microscopic observations also showed marked ultrastructural changes and these changes were more pronounced in $\mathrm{Pb}$ and $\mathrm{Cd}$ co exposure group (group 5) than the $\mathrm{Pb}$ and $\mathrm{Cd}$ alone exposed groups (groups 3 and 4), respectively. We also observed a significant $(\mathrm{p}<0.05)$ elevation in the serum creatinine levels. Use of the NAC counteracted the all toxic effects by chelating these metals, thereby reducing their accumulation and NAC also demonstrated its antioxidant properties, as judged by a significant reduction in the serum creatinine levels.
\end{abstract}

Conclusion: We conclude that the co-existence of these metals showed a positive pharmacodynamic interaction and significant improvement was noticed after NAC therapy.

Key words: cadmium, lead, N-Acetyl-L-Cysteine, rat

\section{I ntroduction}

Heavy metals are increasingly being recognized as potential environmental pollutants. Lead $(\mathrm{Pb})$ and Cadmium $(\mathrm{Cd})$ are often released simultaneously into the environment from a number of natural and manmade sources. Adverse health effects caused by combined exposure to $\mathrm{Pb}$ and $\mathrm{Cd}$ have provoked a significant public health concern $[1,2]$. $\mathrm{Pb}$ and $\mathrm{Cd}$ are divalent cations with a high propensity to settle in the proximal tubules of the nephron, leading to nephrotoxicity [3, 4]. Moreover, co existence of these metals exhibit synergism in their toxic effects $[5,6]$. Long-term exposure to these metals will lead to renal tubular damage by accumulation in the kidney once the critical tissue threshold level is reached [7]. Many authors proposed that the formation of free radicals is the most important molecular mechanism of their toxicity [8-10]. Excess intake/ accumulation of these metals cause depletion of endogenous glutathione

Copyright: The authors. This article is an open access article licensed under the terms of the Creative Commons Attribution License (http://creativecommons.org/licenses/by/2.0) which permits unrestricted use, distribution and reproduction in any medium, provided the work is properly cited.
(GSH) [11], decreased activities of Super oxide dismutase (SOD), Glutathione peroxidase (GPx), Catalase, and significant elevation of Thiobarbituric acid reactive substances (TBARS) in the kidney, thus suggesting increased renal oxidative stress $[12,13]$. Oxidative stress could be responsible for renal damage and there by increase serum creatinine concentration which is a sensitive indicator of renal damage.

$\mathrm{N}$-acetyl-L-cysteine (NAC), a potent antioxidant, is a sulfur-based amino acid needed for GSH synthesis, and is a natural antioxidant enzyme produced in the body to fight free-radical activity and has been used clinically since decades for the treatment of many diseases. GSH is a sulfur-containing nucleophilic substance found in high concentrations in the kidney. NAC has been also used as a chelator of heavy metals to protect against oxidative stress and prevent damage to cells [14-17].

The goal of our study was to determine the histopathological and ultrastructural changes in kidney due to the interaction of $\mathrm{Pb}$ and $\mathrm{Cd}$ and their amelioration with NAC. 


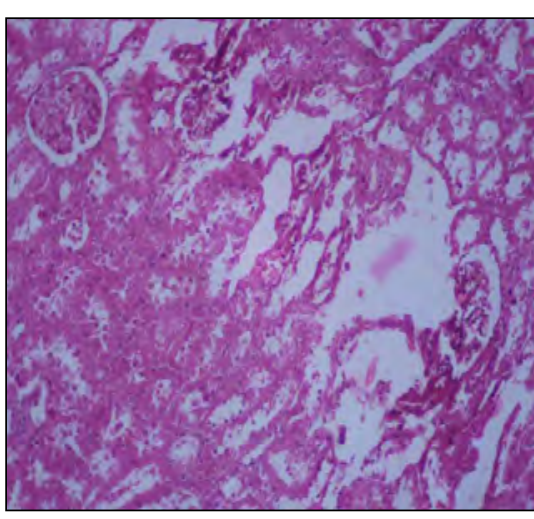

Figure-1. Photomicrograph of kidney showing dilated, ruptured tubules, mild to severe fatty change, reduced glomerular space and with few ruptured glomeruli. $H \& E$ X200 (Group 3)

\section{Materials and Methods}

Chemical Reagents: Lead acetate, Cadmium chloride and all the other chemicals used in our experiments were purchased from SRLPvt. Ltd., Mumbai.

Animals: Male albino rats of Wistar strain weighing about 200-250 g were procured from the National Institute of Nutrition, Hyderabad, Andhra Pradesh. The use of animals in this study were approved by the Committee for the Purpose of Control and Supervision of Experiments on Animals (CPCSEA) (approval no. 5/I/10).

Experimental design: The study was carried out for 3 months on 48 male Wistar rats randomly divided into 8 groups with six rats in each group. (OECD 408 GIUDLINES (1998), Oral toxicity for 90 days).

Group 1: Normal control.

Group-2: N-acetyl-L-cysteine (NAC) @ 300 mg / kg body weight.

Group-3: Lead toxic control (Lead acetate @ 1000 ppm in feed).

Group-4: Cadmium toxic control (Cadmium chloride @ 300 ppm in feed).

Group-5: Lead and Cadmium toxic control @ 1000 and 300 ppm, respectively, in feed.

Group-6: Lead and NAC @ 1000 ppm in feed and @ $300 \mathrm{mg} / \mathrm{kg}$ body weight respectively

Group-7: Cadmium and NAC @ 300 ppm in feed and @ $300 \mathrm{mg} / \mathrm{kg}$ body weight respectively

Group-8: Lead, Cadmium and NAC @ 1000, 300 ppm in feed and @300mg/kg body weight respectively.

$\mathrm{Pb}$ and $\mathrm{Cd}$ were used in the form of lead acetate and cadmium chloride and were given in the form of mash feed, while NAC was administered via oral gavage by diluting in distilled water.

Biochemical study: Blood collection was carried out at monthly intervals for creatinine estimation after initiation of the drug administration till the end of experiment. Feed was withdrawn $12 \mathrm{~h}$ before the blood collection and blood was collected from retro-orbital plexus into serum vacutainers and centrifuged at 3000 RPM for $15 \mathrm{~min}$, and serum was separated and stored at

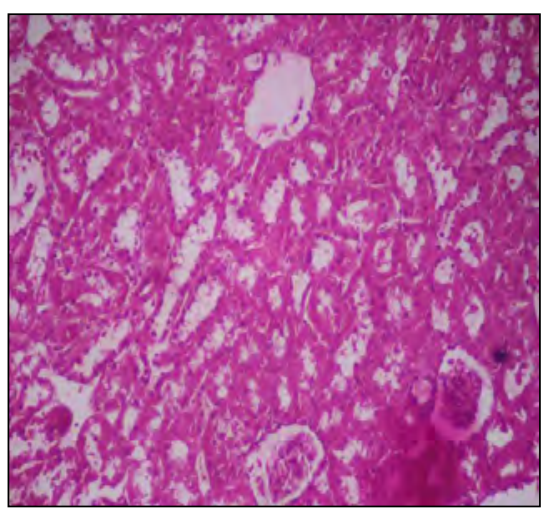

Figure-3. Photomicrograph of kidney showing ruptured glomeruli, severe fatty change, reduced glomerular space and with loss of few glomeruli. H\&E X200 (Group 5)

$-20^{\circ} \mathrm{C}$ for future use. Analysis of creatinine was done according to the instructions provided in the kit supplied by SRL Pvt. Ltd., Mumbai.

Histopathological study: Rat kidneys were collected at the end of $3^{\text {rd }}$ month for which rats were fasted overnight and sacrificed by cervical decapitation. Kidneys were then excised, weighed, dissected out and washed with ice cold saline. Approximately $0.2 \mathrm{~g}$ of renal tissue was preserved in $10 \%$ neutral buffer formalin for histological studies and the fixed tissues were processed and stained with routine Hematoxylin and Eosin (H \& E) stain [18] at the Department of Veterinary Pathology, College of Veterinary Science, Rajendranagar, Hyderabad.

Electron microscopic study: Small pieces of kidney samples were transferred to vials and fixed in $3 \%$ gluteraldehyde in $0.05 \mathrm{M}$ phosphate buffer $(\mathrm{pH} 7.2)$ for $24 \mathrm{~h}$ at $4^{\circ} \mathrm{C}$ and post-fixed in $2 \%$ aqueous osmium tetroxide in the same buffer for $1 \mathrm{~h}$. The sections were stained with saturated aqueous uranyl acetate and counter stained with $4 \%$ lead citrate [19] and were observed at various magnifications under a transmission electron microscope (Model: Hitachi, H7500) at RUSKA Laboratory, College of Veterinary Science, Hyderabad, India.

Estimation of heavy metals: The concentrations of $\mathrm{Pb}$ and $\mathrm{Cd}$ [20] were estimated by digesting the tissue samples in a reagent grade of nitric acid-perchloric acid (2:1) mixture and concentrations were measured by Atomic Absorption Spectrophotometer (Model; F S 120), at the Department of Environmental pollutants and micro nutrients, Agricultural Research Institute, Rajendranagar, Hyderabad.

Analysis of variance: Results were analyzed by oneway analysis of variance (ANOVA) using SPSS (Ver. $10.00)$ followed by Duncan test at $5 \%(\mathrm{p}<0.05)$ level of significance. Results were expressed as mean \pm standard error.

\section{Results and Discussion}

In the present study, the sections of kidney 


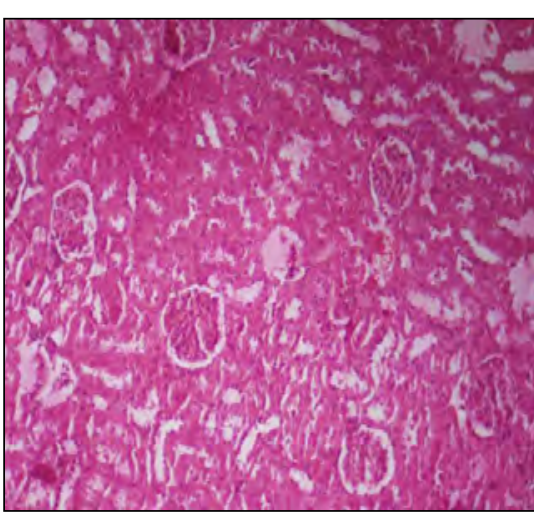

Figure-4. Photomicrograph of kidney showing mild degenerative changes in and around glomeruli. H\&E X200 (Group 6)

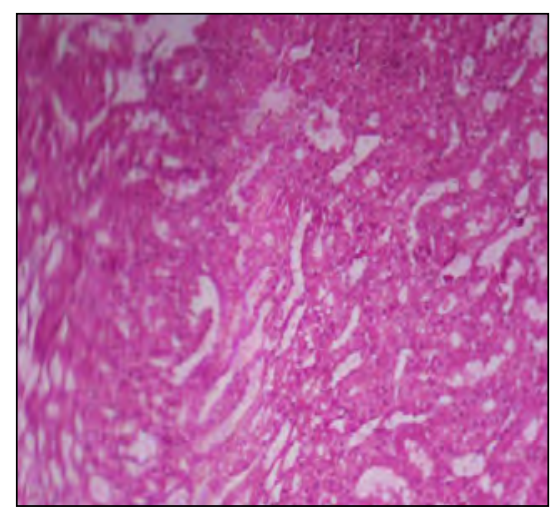

Figure-5. Photomicrograph of kidney showing mild degenerative changes. H\&E X200 (Group 7)

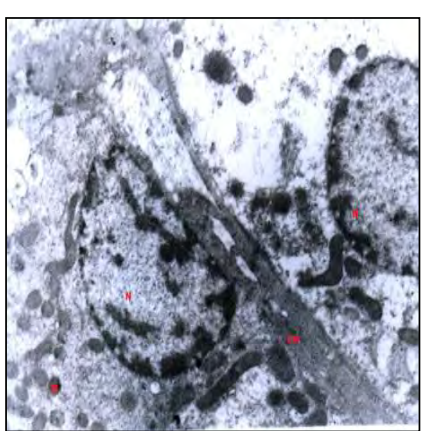

Figure-7. TEM of kidney showing vacuolation (V), swollen nucleus vacuolation (V) with dense material, $(\mathrm{N})$, margination of chromatin and swollen nucleus $(\mathrm{N})$, margination irregular mitochondria (M). of chromatin and irregular
(Group 4) $2440 \mathrm{mitochondria(M).}$ (Group 7) $3440 \mathrm{X}$ revealed dilated, ruptured tubules, mild to severe fatty change, reduced glomerular space and rupture of few glomeruli in $\mathrm{Pb}$ exposed group (G-3) (Fig. 1), where as Cd exposed group (G-4) showed severe changes in tubules with dilation and severe fatty change and reduced glomerular space (Fig. 2), while $\mathrm{Pb}$ and $\mathrm{Cd}$ co exposed group (G-5) exhibited ruptured glomeruli, severe fatty change, reduced glomerular space and loss of few glomeruli (Fig. 3). The NAC co treated groups 6, 7 and 8 showed mild degenerative changes in and around glomeruli when compared with their respective toxic control groups 3, $4 \& 5$ (Fig. 4, $5 \& 6$ ). Kidney is the primary target organ for accumulation of $\mathrm{Pb}$ and $\mathrm{Cd}$ and long-term exposure damages renal tubules by causing massive local haemorrhage, vascular congestion, focal necrosis, destruction of nucleus, and oedema of renal tissues [21,22]. This damage is due to the generation of free radicals as they are divalent cations that readily bind with oxygen to form Reactive Oxygen Species (ROS). Toxic metals increase production of free radicals and decrease the availability of antioxidant reserves to respond to the resultant damage [23].

Furthermore, the other significant aspect of our study is to decipher the electron microscopic changes induced by these heavy metals. Ultrastructurally, kidney tissue in group 4 (Cd exposed) revealed mild hyperplasia of smooth endoplasmic reticulum, mild to moderately sized vacuoles, condensed mitochondria, vesicles containing dense mass, condensed nuclei with

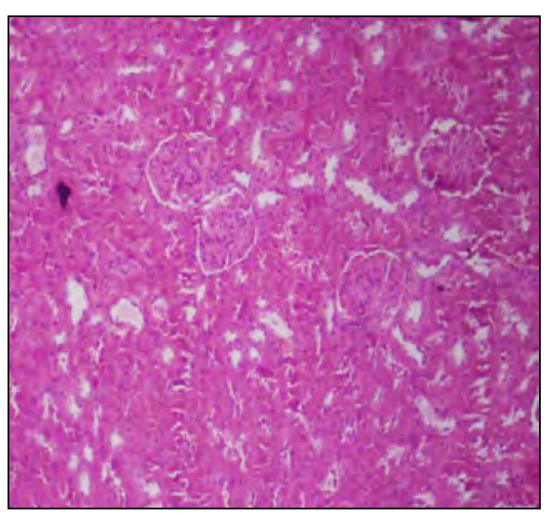

Figure-6. Photomicrograph of kidney showing mild degenerative changes. $H \& E$ X200 (Group 8)

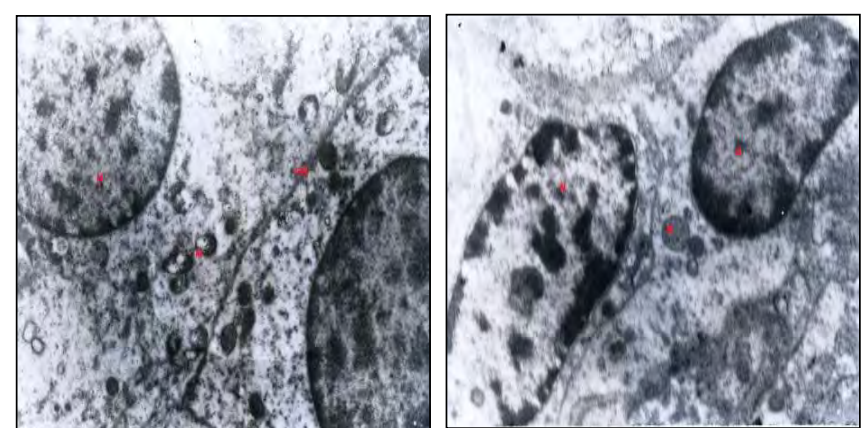

Figure-9. TEM of kidney showing Figure-10. TEM of kidney showing thin cell wall (CW) swollen nucleus vacuolation (V), nucleus (N), intact (N), margination of chromatin and chromatin and non vacuoalated mitochondria (M). (Group 5) 5580X

margination of chromatin and presence of electron dense granular material in neucleolemma and shrunken cell walls (Fig.7). Cd + NAC co treated group (G-7) showed nuclei with dense chromatin scattered throughout nucleolemma, mild condensed mitochondria of varied sizes and shapes, presence of endoplasmic reticulum, chromatin granules, reduced margination of chromatin in nuclei (Fig. 8). $\mathrm{Pb}+\mathrm{Cd}$ co exposed group (G-5) revealed shrunken cell size, condensed nuclei of varied size and shape, indistinct cell organelles, thin cell wall and few condensed and vacuolated mitochondria (Fig. 9). In NAC co treated $(\mathrm{Pb}+\mathrm{Cd}+\mathrm{NAC})$ group $(\mathrm{G}-8)$, chromatin was widely distributed and there was mild hyperplasia of endoplasmic reticulum, tight cell junctions, mild variation in the sizes and shapes of mitochondria without vacuolation and distinct nucleus and nucleolus indicated by electroluscent central area (Fig.10). Our results are in agreement with previous studies dealing with $\mathrm{Pb}$ and $\mathrm{Cd}$ toxicity where ultrastructural changes in the renal tubules and mitochondrial damage were noticed [24-26]. Mainly, the toxic effects involve disruption and loss of mitochondrial cristae together with mitochondrial swelling -which might be due to the formation of free radicals [12].

Histopathological examination revealed that, the effects of either metal alone is less severe when compared to the co exposure $(\mathrm{Pb}+\mathrm{Cd})$ and this was further confirmed by electron microscopic examination of the degree of damage to the mitochondria (as their 
Table-1. Concentrations of serum creatinine in different groups of rats

\begin{tabular}{llll}
\hline Group & $\mathbf{1}^{\text {st }}$ month & $\mathbf{2}^{\text {nd }}$ month & $\mathbf{3}^{\text {rd }}$ month \\
\hline 1. Control & $1.54 \pm 0.09^{\mathrm{aA}}$ & $1.59 \pm 0.06^{\mathrm{aA}}$ & $1.51 \pm 0.07^{\mathrm{aA}}$ \\
2. N-Acetyl L- cysteine & $1.53 \pm 0.08^{\mathrm{aA}}$ & $1.59 \pm 0.04^{\mathrm{aA}}$ & $1.74 \pm 0.04^{\mathrm{aA}}$ \\
3. Lead toxic control & $4.13 \pm 0.04^{\mathrm{CA}}$ & $5.39 \pm 0.14^{\mathrm{CB}}$ & $5.78 \pm 0.13^{\mathrm{bB}}$ \\
4. Cadmium toxic control & $4.30 \pm 0.05^{\mathrm{CA}}$ & $5.66 \pm 0.11^{\mathrm{CB}}$ & $6.12 \pm 0.08^{\mathrm{CB}}$ \\
5. Lead + Cadmium toxic control & $4.74 \pm 0.12^{\mathrm{cA}}$ & $5.74 \pm 0.09^{\mathrm{CB}}$ & $7.21 \pm 0.09^{\mathrm{cC}}$ \\
6. Lead + NAC & $2.81 \pm 0.04^{\mathrm{bC}}$ & $2.20 \pm 0.03^{\mathrm{BC}}$ & $1.63 \pm 0.03^{\mathrm{aA}}$ \\
7. Cadmium+ NAC & $2.94 \pm 0.06^{\mathrm{bC}}$ & $2.32 \pm 0.06^{\mathrm{bC}}$ & $1.71 \pm 0.04^{\mathrm{aA}}$ \\
8.Lead + Cadmium + NAC & $3.03 \pm 0.08^{\mathrm{bC}}$ & $2.24 \pm 0.08^{\mathrm{bC}}$ & $1.59 \pm 0.03^{\mathrm{aA}}$ \\
\hline
\end{tabular}

Values are expressed as mean \pm standard error $(n=6)$

Means with different alphabets as superscripts differ significantly $(p<0.05)$; Capital alphabets are used for horizontal comparison and small alphabets are used for vertical comparison

Table-2. Concentrations of $\mathrm{Pb}$ and $\mathrm{Cd}$ in different groups of rats.

\begin{tabular}{|c|c|c|c|c|c|c|c|c|}
\hline \multirow[t]{2}{*}{ Concentration (ppm) } & \multicolumn{3}{|c|}{ Control groups } & \multicolumn{2}{|c|}{ Toxic control groups } & \multicolumn{3}{|c|}{ Therapeutic groups } \\
\hline & Group1 & Group2 & Group3 & Group4 & Group 5 & Group 6 & Group 7 & Group 8 \\
\hline $\begin{array}{l}\mathrm{Pb} \text { levels } \\
\text { Cd levels }\end{array}$ & $\begin{array}{l}\mathrm{BDL} \\
\mathrm{BDL}\end{array}$ & $\begin{array}{l}\text { BDL } \\
\text { BDL }\end{array}$ & $\begin{array}{l}23.88 \pm 0.35^{\mathrm{b}} \\
\mathrm{BDL}\end{array}$ & $\begin{array}{l}\mathrm{BDL} \\
8.06 \pm 0.15^{\mathrm{b}}\end{array}$ & $\begin{array}{l}24.54 \pm 0.57^{b} \\
8.14 \pm 0.17^{b}\end{array}$ & $\begin{array}{l}8.13 \pm 0.30^{\mathrm{a}} \\
\mathrm{BDL}\end{array}$ & $\begin{array}{l}\text { BDL } \\
0.68 \pm 0.04^{\mathrm{a}}\end{array}$ & $\begin{array}{l}7.46 \pm 0.43^{a} \\
0.64 \pm 0.03^{2}\end{array}$ \\
\hline
\end{tabular}

Values are expressed as mean \pm standard error $(n=6)$

Means with different small alphabets as superscripts differ significantly $(p<0.05)$ for vertical comparison

numbers were reduced) and endoplasmic reticulum. With respect to the mitochondrial ultra structure, severe damage was noticed in the combined exposed groups than that of single metal exposure groups. $\mathrm{Pb}$ and/or $\mathrm{Cd}$ exposure induces damage to the mitochondria of kidney cortex which results in decreased synthesis of ATP and uncouples oxidative phosphorylation due to the formation of ROS [27].

These results were supported by elevation in the concentrations of serum creatinine which is a biomarker of kidney damage. The concentrations of serum creatinine in toxic control groups (3,4 and 5) were significantly $(\mathrm{p}<0.05)$ higher at different time intervals, and this increase was more pronounced in $\mathrm{Pb}$ $+\mathrm{Cd}$ combination group (G-5), which indicated their synergistic toxic effect (Table-1). The serum creatinine concentrations in NAC treated groups 6, 7 and 8 were significantly decreased and these decreased concentrations were comparable to that of control groups 1 and 2 at different time intervals. These findings are in conformity with those obtained in other relevant studies on this particular issue [28, 29].

NAC co-treatment has reduced the extent of damage to renal tissue as evident from decreased serum creatinine levels. This decrease in concentration of creatinine occurs by increasing the intra cellular Glutathione concentration [30-31] Histological changes in the renal tissues improved significantly in NAC treated groups and this was also evident in the ultra structural studies [32]. NAC is an excellent chelator of heavy metals and is also a scavenger of free radicals [15] and will therefore reduce the concentrations of these metals in the renal tissue.

\section{Conclusion}

The present investigation enunciated that $\mathrm{Pb}$ and $\mathrm{Cd}$ induced renal tissue alterations histologically and ultra structurally were more pronounced in the combination group than in the individual metals exposed groups. On the other hand, use of NAC counteracted the adverse effects of $\mathrm{Pb}$ and $\mathrm{Cd}$ induced renal damage to a major extent suggesting its chelating action on heavy metals.

\section{Authors' contributions}

BA: designed and conducted the experiment under the guidance of AGR. AAK: Helped in study the electronmicroscopic changes in the kidney tissue after treating the rats with lead and cadmium. GA and $\mathrm{CH}$ : helped in analysis of various parameters.

\section{Acknowlegements}

The authors are thankful to Dr. Y. Ramana Reddy, Professor, Department of Animal Nutrition for providing chemicals used in this experiment. The funds were provided by Sri Venkateswara Veterinary University (SVVU)- Tirupati toward B. Anil Kumar's $\mathrm{Ph} . \mathrm{D}$. dissertation.

\section{Competing interests}

The authors declare that they have no competing interests.

\section{References}

1. Brender, J. D., Suarez, L., Felkner, M., Gilani, Z., Stinchcomb, D. and Moody, K. (2006) Maternal exposure to Arsenic, cadmium, lead, and mercury and neural tube defects in offspring. Environ. Res., 101:132-139.

2. Walker, L. A., Simpson, V. R., Rockett, L., Wienburg, C. L. and Shore, R. F. (2007) Heavy metal contamination in bats in Britain. Environ. Pol., 148:483-490.

3. Patra, R. C., Rautray, A. K. and Swarup, M. D. (2011) Review Article Oxidative Stress in Lead and Cadmium Toxicity and Its Amelioration. Vet. Med. Int., 20:2011-2014.

4. Karimi, M. M., Sani, M. J., Mahmudabadi, A. Z., Sani, A. J. and Khatibi, S. R. (2012) Effect of Acute Toxicity of Cadmium in Mice Kidney Cells. Ir. J. Toxicol., 6 (18); 691698.

5. Bizarro, P., Acevedo, S., Cabrera, G. N., Galante, P. M., Pasos, F. and Costa, M. R. (2003) Ultrastructural modifications in the mitochondrion of mouse Sertoli cells after inhalation of lead, cadmium or lead-cadmium mixture. Reprod. Toxicol., 17:561-566. 
6. Kaji, T., Suzuki, M., Yamamoto, C., Mishima, A., Sakamotom, M. and Kozuka, H. (1995) Severe damage of cultured vascular endothelialcell monolayer after simultaneous exposure to cadmium and lead. Arch. Environ. Contam. Toxicol., 28:168-172.

7. Missoun, F., Slimani, M. and Aoues, A. (2012) Toxic effect of lead on kidney function in Wistar rat. A. J. Biochem. Res., 4(2): 21-27.

8. Cuypers, M., Plusquin, T. and Remans., (2010) Cadmium stress: ant oxidative challenge," BioMet., 23(5): 927-940.

9. Yan, C., Zhang, X., Deng, J., Zhao, Q. and Xu, H. (2012) Lead and cadmium-induced oxidative stress impacting mycelial growth of Oudemansiella radicata in liquid medium alleviated by microbial siderophores . W.J. Micr. Biote., 28(4): 1727-1737.

10. Kumar, B. A. and Reddy, A.G. (2012) Effect of N-Acetyl LCysteine (NAC) against oxidative stress - induced neurotoxicity due to lead, cadmium and combination in wistar rats. Int. J. Pharm. Bio. Sci., 3(4): 403-418.

11. Kara, H., Karatas, F. and Canatan, H. (2005) Effect of Single Dose Cadmium Chloride Administration on Oxidative Stress in Male and Female Rats. Turk. J. Vet. Ani. Sci., 29: $37-42$.

12. Wang, L., Wang, H., Hu, M., Cao, J., Chen, D. and Liu, Z. (2009) Oxidative stress and apoptotic changes in primary cultures of rat proximal tubular cells exposed to lead. Arch. Toxicol., 83: 417-427.

13. Wang, J., Yang, Z., Lin, L., Zhao, Z., Liu, Z. and Liu, X. (2012) Protective effect of naringenin against lead-induced oxidative stress in rats. Biol. Tr. Elem. Res., 146(3):354-9.

14. Blanusa, M., Varnai, V. D., Piase, M. and Kostial, K. (2005) Chelators as antidotes of metal toxicity: therapeutic and experimental aspects. Cur. Med. Chem., 12: 2271-2794.

15. Clement, S. L., Hellier, B. C., Elberson, L. R., Staska, R. T. and Evans, A. A. (2007) Flies (Diptera: Muscidae: Calliphoridae) are efficient pollinators of Allium ampeloprasum L. (Alliaceae) in field cages. J. Econ. Entomol., 100: 131-135.

16. Pereira, L. V., Shimizu, M. H., Rodrigues, L. P., Leite, C. C., Andrade, L. and Seguro, A. C. (2012) N-acetylcysteine protects rats with chronic renal failure from gadoliniumchelate nephrotoxicity. P.L.S. On., 7(7): 39528.

17. Campos, R., Shimizu, M. H., Volpini, R. A., Bragança, A. C., Andrade, L., Lopes, F. D., Olivo, C., Canale, D. and Seguro, A. C. (2012) N-acetylcysteine prevents pulmonary edema and acute kidney injury in rats with sepsis submitted to mechanical ventilation. A. J. Physiol. Lu. Cel. Mol. Physiol., 302(7): 640-50.

18. Singh, U. B. and Sulochana, S. (1997) Handbook of Histological and Histochemical Techniques. Premier Publishing House, Hyderabad, India. $2^{\text {nd }}$ edn., Page no. 5-41.

19. Bozzola, J. J. and Russell, L. D. (1999) Electron Microscopy: Principles and Techniques for Biologists. Jones and Bartlett, Boston. $2^{\text {nd }}$ edn., Page no.54-67
20. Sawhney, S. K. and Randhir singh. (2007) Analysis of plant tissues introductory practical Biochemistry Narosh publishing House private limited $2^{\text {nd }}$ edition; pp 141-143.

21. Obianime, A. W. and Roberts, I. I. (2009) Antioxidants, cadmium-induced toxicity, serum biochemical and the histological abnormalities of the kidney and testes of the male Wistar rats. N. J. Physiol. Sci., 2: 177-185.

22. Wiostowski, T., Dmowski, K. and Ostaszewska, B. E. (2010) Cadmium accumulation, metallothionein and glutathione levels, and histopathological changes in the kidneys and liver of magpie (Pica pica) from a zinc smelter area. Ecotoxicol., 19:1066-1073.

23. Salinska, A., Wiostowski, T. and Zambrzycka, E. (2012) Effect of dietary cadmium and/or lead on histopathological changes in the kidneys and liver of bank voles Myodes glareolus kept in different group densities. Ecotoxicol., 21(8): 2235-2243.

24. Wang, L., Li, J. and Liu, Z. (2010) Effects of lead and/or cadmium on the oxidative damage of rat kidney cortex mitochondria. Biol. Tr. El. Res., 137: 69-78.

25. Besirovic, H., Alic, A., Prasovic, S., Drommer, W. (2010) Histopathological Effects of Chronic Exposure to Cadmium and Zinc on Kidneys and Gills of Brown Trout (Salmo trutta m. fario). Turk. J. Fish. Aqu. Sci., 10: 255-262.

26. Reyes, J.L., Jijon, E.M., Munoz, R.R., Garcia, P.B., Garcia, Y.D. and Namorado, M.C.(2013)Tight Junction Proteins and Oxidative Stress in Heavy Metals-Induced Nephrotoxicity. Biomed. Res. Int., 1-14.

27. Foster, K, A., Galeffi, F., Gerich, F, J., Turner, D, A. and Muller, M. (2006) Optical and pharmacological tools to investigate the role of mitochondria during oxidative stress and neurodegeneration. Prog. Neurobiolol., 79:136-171.

28. Aslam, M., Ahmad, S. T., Dayal, R., Javid, K., Umar, S., Asiaf, A., Nafees, S., Bhat, J. U., Wani, A., Samim, M. and Singh, S. (2012) Nephroprotective action of peucedanum grande against cadmium chloride induced renal toxicity in wistar rats. EXCLIJ., 11:444-452.

29. Wang, L., Li, J. and Liu, Z. (2010) Effects of lead and/or cadmium on the oxidative damage of rat kidney cortex mitochondria. Bio.Tr. Elem. Res., 137: 69-78.

30. Pillai, P., Pandya, C., Gupta, S. and Gupta, S. (2010) Biochemical and molecular effects of gestational and lactational coexposure to lead and cadmium on ovarian steroidogenesis are associated with oxidative stress in F1 generation rats. J. Biochem. Mol. Toxicol.. 24(6):384-94.

31. Jovanovic, M.J., Nikolic, R.S., Kocic, G.M., Krstic, N.S. and Krsmanovic, M.M. (2013) Glutathione protects liver and kidney tissue from cadmium and lead-provoked lipid peroxidation. J. Serb. Chem. Soci., 78 (2) 197-207.

32. Kaplan, M., Atakan, I. H., Aydogdu, N., Aktoz, T., Ozpuyan, F. and Seren, G. (2008) Influence of N-acetylcysteine on renal toxicity of cadmium in rats. Ped. Nephrol., 23: 233-241. 